\title{
Aplikasi Buku Saku Pramuka Berbasis Android
}

\author{
Ismail Mohidin ${ }^{*}$ ) \\ Saprina Mamase ${ }^{2 *}$ \\ Program Studi Teknik Informatika, Politeknik Gorontalo \\ email : is,mohidin@poligon.ac.id \\ email : Saprinamamase@poligon.ac.id
}

\begin{abstract}
ABSTRAK - Pendidikan kepramukaan adalah sebagai salah satu pilar pendidikan kaum muda di Indonesia, dituntut untuk dapat lebih berkontribusi secara nyata dalam hidup dan kehidupan berbangsa dan bernegara, maka dari itu penulis membuat aplikasi buku saku pramuka berbasis android dengan tujuan agar para pemula baik anak SD maupun dewasa bisa mempelajari ilmu kepramukaan. Penulis melakukan pengujian aplikasi buku saku pramuka pada masyarakat, sehingga hasil uji coba dari 16 sampel yaitu 7 orang yang menggunakan smartphone dan 9 orang tidak memiliki smartphone, ternyata dengan menggunakan aplikasi buku saku pramuka ini pengguna merasa lebih terpacu untuk mempelajari ilmu kepramukaan dibandingkan ketika pengguna membaca buku saku pramuka yang dicetak, karena di dalam aplikasi buku saku pramuka ini sudah dilengkapi dengan fitur animasi dan suara untuk membantu pengguna memahami ilmu kepramukaan.
\end{abstract}

Kata Kunci : Panduan Pramuka, Suara, Animasi, Android.

\section{PENDAhuluan}

Gerakan Pramuka sebagai lembaga pendidikan nonformal yang tujuan utamanya adalah membentuk kaum muda yang berakhlak mulia, menanamkan semangat kebangsaan, dan meningkatkan keterampilan menjadi penting peranannya. Pendidikan kepramukaan adalah sebagai salah satu pilar pendidikan kaum muda di Indonesia, dituntut untuk dapat lebih berkontribusi secara nyata dalam hidup dan kehidupan berbangsa dan bernegara. (Sunardi Andri Bob 2013: 4, 5, 6)

Namun sayangnya ilmu kepramukaan ini hanya bisa didapatkan didalam organisasi pramuka ini saja, apalagi sekolah sekolah yang berada di pelosok desa yang sangat jarang ada yang membentuk organisasi seperti ini. Adapun yang mengikuti pramuka hanyalah sekedar mengikuti saja dalam rangka menggugurkan kewajiban semata tanpa memahami ilmu tentang kepramukaan.

Seiring berkembangnya zaman seperti saat ini, sudah banyak teknologi yang disesuaikan dengan kebutuhan manusia. Salah satu teknologi yang banyak digunakan oleh masyarakat saat ini yaitu seperti smartphone yang menggunakan sistem operasi Android. Android adalah suatu sistem operasi yang berbasis Linux untuk telepon pintar (SmartPhone) atau pun pada Komputer Tablet, Android juga sudah menyediakan platform terbuka yang sehingganya bisa

\author{
Ayidil Kai ${ }^{3 *}$ \\ Program Studi Teknik Informatika, Politeknik Gorontalo \\ email : ayidilkai@gmail.com
}

dikembangkan sendiri ]oleh para pencinta Android. (Amperiyanto Tri 2014: 1, 2).

Ada pun aplikasi buku saku pramuka berbasis android yang beredar saat ini juga kurang menarik dikarenakan aplikasinya hanya berisikan teori semata belum menggunakan animasi dan suara, kemudian ilmu ilmunya tidak digabungkan dalam 1 aplikasi, sehingga pengguna pun pasti akan merasakan bosan dengan aplikasinya, Maka dari itu untuk menanggulangi permasalahan di atas saya akan membuat aplikasi "Buku Saku Pramuka Berbasis Android" yang bisa digunakan di dalam SmartPhone saat ini, kemudian ilmunya pun sudah digabungkan di dalam satu aplikasi dan sudah menggunakan animasi dan suara sehingga lebih mudah untuk memahami oleh pengguna dan mudah mendapatkan ilmu tentang kepramukaan lebih khususnya bagi para pemula.

\section{METODOLOGI PENELITIAN}

\subsection{Lokasi dan Waktu Penelitian}

Dalam penelitian kali ini penulis melakukan penelitian di Kwartir Cabang Gerakan Pramuka Kota Gorontalo, Jl. Sarini Abdullah, Kel, Limba U 2, Kec. Kota Selatan. Penulis akan meneliti selama 5 bulan, terhitung dari bulan Januari sampai Mei 2014.

\subsection{Metode Pengumpulan Data}

Untuk mendapatkan data yang dibutuhkan dalam penelitian ini maka penulis melakukan pengumpulan data dengan menggunakan metode wawancara. Data yang didapatkan penulis setelah wawancara dengan staf Kwartir Cabang Gerakan Pramuka Kota Gorontalo, yaitu sebuah buku saku Pramuka yang bersifat manual.

\subsection{Analisis Data}

Bardasarkan hasil penelitian di kwartir cabang penulis mendapati bahwa analisis data dari pencarian informasi kepramukaan dengan menggunakan buku biasanya yaitu diawali dengan mengambil buku, kemudian melihat daftar isi pada buku tersebut, setelah pengguna mendapati materi yang ingin dia pelajari pengguna langsung membuka halaman sesuai dengan apa yang ada pada daftar isi materi buku tersebut, jika pengguna ingin melihat materi yang lain maka pengguna melihat kembali daftar materinya, jika tidak maka pengguna menutup buku tersebut seperti apa yang di tunjukan pada Gambar 2.1 Skema Alur Buku Saku Pramuka. 


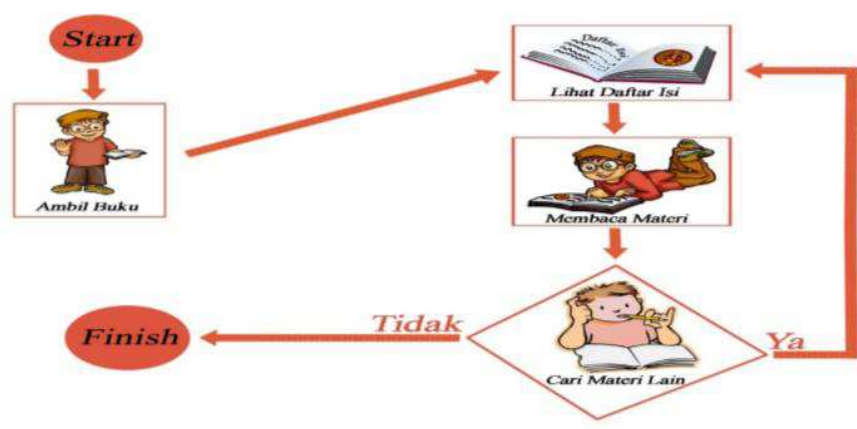

Gambar 2.1 Skema Alur Buku Saku Pramuka

\subsection{Use Case Aplikasi Buku Saku Pramuka}

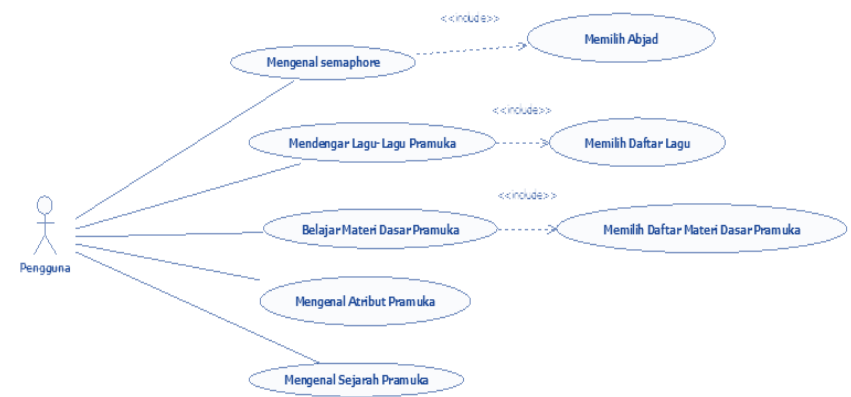

Gambar 2.2 Use Case Aplikasi Buku Saku Pramuka

\subsection{Activity Pengenalan Semaphore}

Tabel 2.1 Activity Pengenalan Semaphore

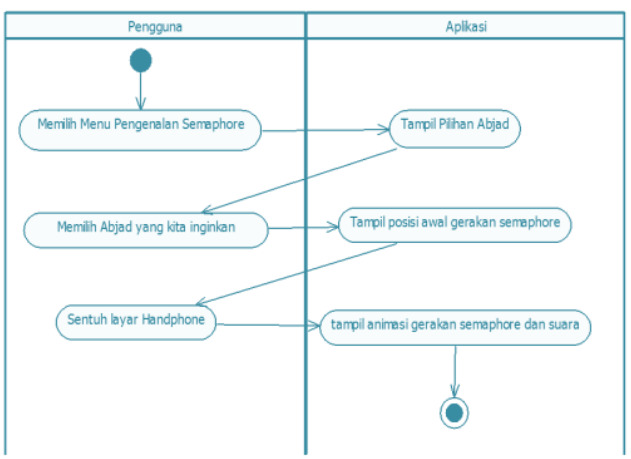

\subsection{Activity Lagu-Lagu Pramuka}

Tabel 2.2 Activity Lagu-Lagu Pramuka

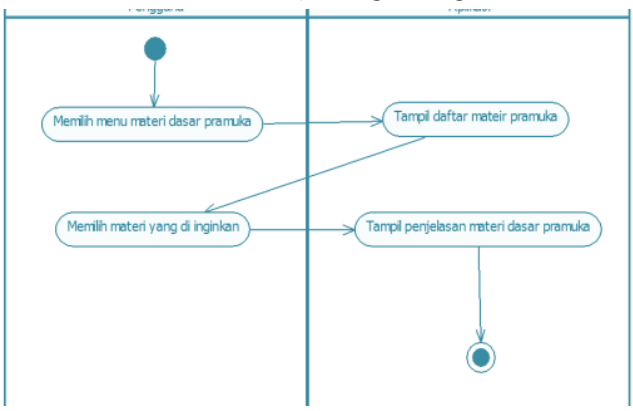

\subsection{Activity Belajar Materi Dasar Pramuka}

Tabel 2.3 Activity Belajar Materi Dasar Pramuka

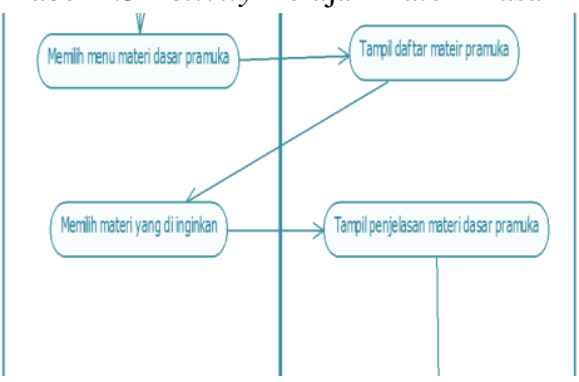

2.8 Activity Pengenalan Atribut Pramuka

Tabel 2.4 Activity Pengenalan Atribut Pramuka

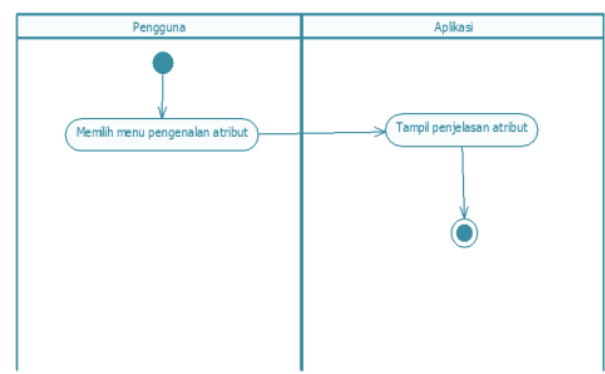

\subsection{Activity Pengenalan Sejarah Pramuka}

Tabel 2.5 Activity Pengenalan Sejarah Pramuka

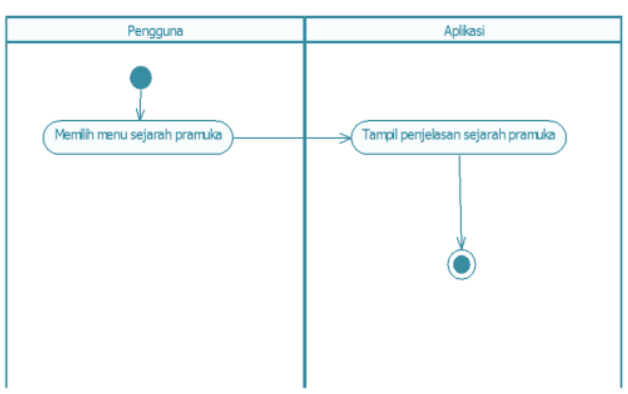

\subsection{Sequence Diagram}

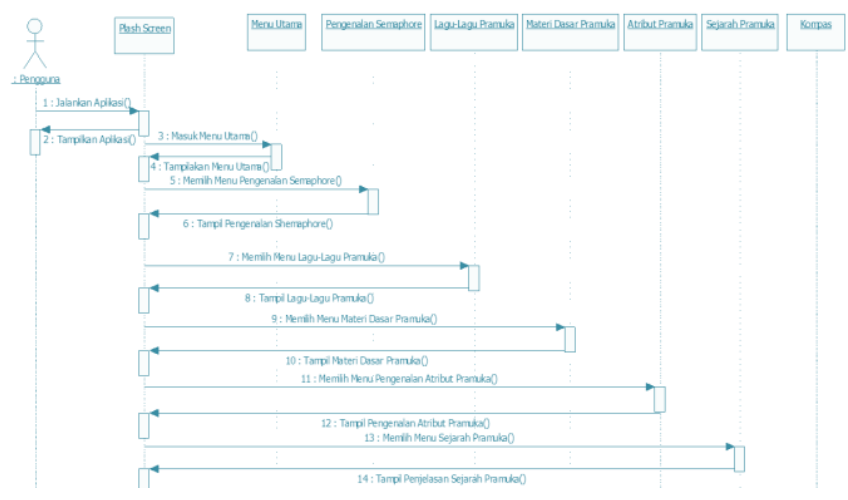

Gambar 2.3 Sequence Diagram 


\section{HASIL DAN PEMBAHASAN}

\subsection{Hasil}

\subsubsection{Menu Utama}

Pada tampilan menut utama berisikan tampilan awal aplikasi. Di dalam tampilan menu utama, menyediakan beragam pilihan yakni dari menu Mengenal Semaphore, Mendengar Lagu-lagu Pramuka, Belajar Materi dasar, Mengenal Atribut Pramuka, Mengenal Sejarah Pramuka, Melihat Kompas, Tentang Aplikasi.

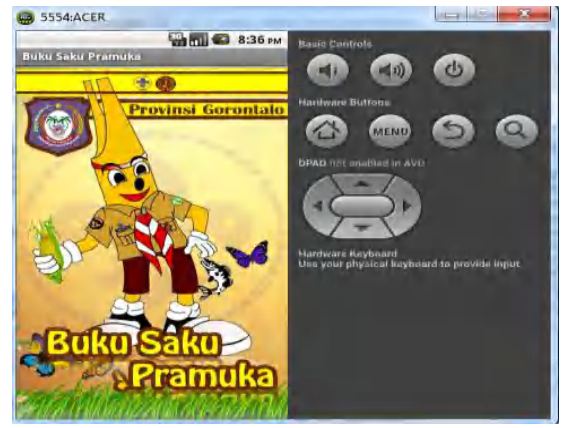

Gambar 3.1 Tampilan awal aplikasi buku saku pramuka

\subsubsection{Daftar Menu}

Daftar menu berisikan pengenalan Semaphore, Mendengar Lagu-lagu Pramuka, Belajar Materi dasar, Mengenal Atribut Pramuka, Mengenal Sejarah Pramuka, Melihat Kompas, Tentang Aplikasi.

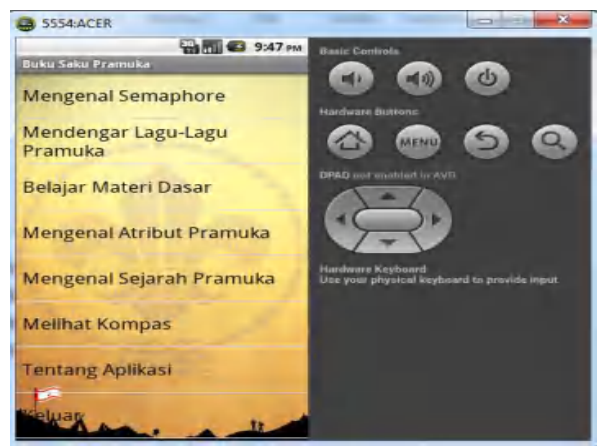

Gambar 3.2. Daftar Menu

\subsubsection{Tampilan Menu Mengenal Semaphore}

Dalam tampilan ini aplikasi menyediakan pilihan huruf abjad A sampai $\mathrm{Z}$ yang akan dipilih oleh pengguna seperti pada tampilan dibawah ini.

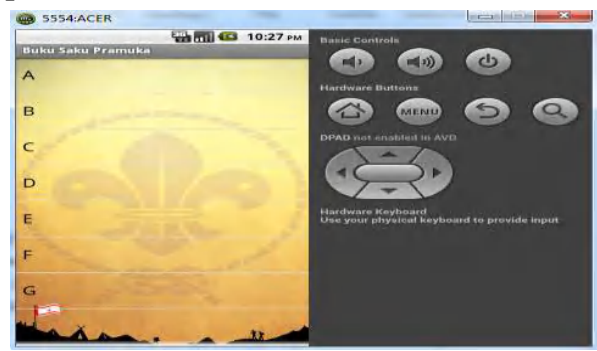

Gambar 3.3 Tampilan Menu Mengenal Semaphore

\subsubsection{Tampilan Animasi Abjad}

Berikut adalah tampilan animasi abjad (A) yang sudah di pilih oleh pangguna.
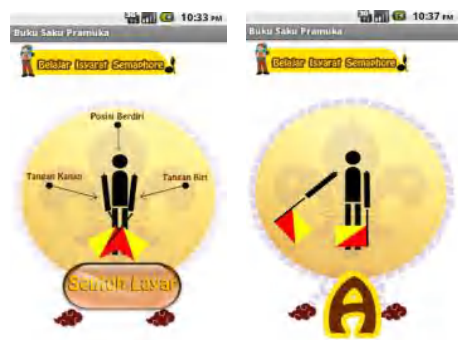

Gambar 3.4 Tampilan Animasi Abjad.

Gambar 3.4 Tampilan Animasi Abjad di atas yakni gambar animasi abjad A semphore sebelum dan sesudah menyentuh layar ketika pengguna sudah memilih abjad huruf A yang ingin dipelajari bagaimana gerakan abjad dengan semaphore, begitu pun demikian dengan abjad yang lainya.

\subsubsection{Menu Mendengar Lagu-Lagu Pramuka}

Berikut adalah tampilan menu Mendengar lagu-lagu Pramuka, didalam menu ini aplikasi menyediakan beberapa lagu yang akan dipilih oleh pengguna yaitu di antaranya Himne Pramuka, Alam Luas, Berkemah, Api Menyala, Gerak Pramuka, Praja Muda Karana, Hulonthalo Lipu'u, Bitea, dan Binde Biluhuta.

Dalam menu Mendengar lagu-lagu pramuka ini ditambah dengan lagu tradisional gorontalo agar pangguna (pemula) juga mengetahui lagu-lagu tradisional seperti pada gambar 3.5 Daftar Lagu Menu Mendengar Lagu-Lagu Pramuka.

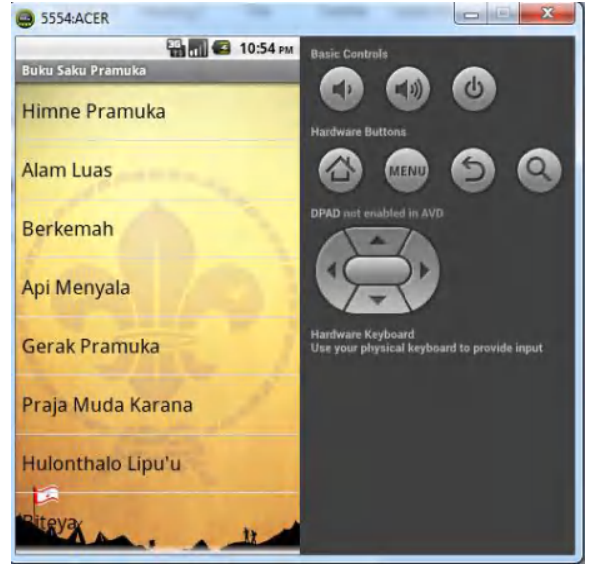

Gambar 3.5 Daftar Lagu Menu Pramuka

\subsection{Lagu Yang Dipilih}

Dibawah ini adalah tampilan lagu yang sudah dipilih oleh pengguna.pengguna bisa langsung mendengarkan lagu yang sudah di pilih, didalam menu lagu ini,agar bisa di atur pemutaran lagu sesuai dengan keinginan maka aplikasi menyediakan 3 button untuk bisa dioperasikan oleh penggguna yaitu Button Play, Button Pause, Dan Button Stop, begitupun sama halnya dengan menu lagu-lagu yang lainya 
yakni pengguna bisa mengoperasikan button, bisa langsung mendengar lagu dan melihat langsung lirik lagu yang akan dimainkan agar lebih mudah dihafal oleh pemula seperti pada Gambar 3.6 Tampilan lagu yang di pilih.

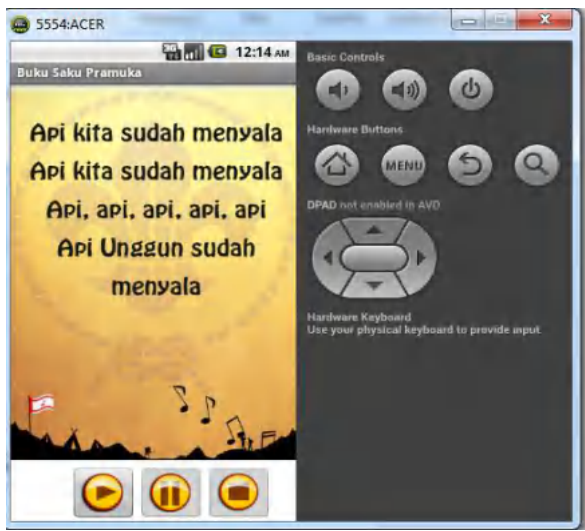

Gambar 3.6 Tampilan lagu yang di pilih.

\subsection{Menu Belajar Materi Dasar}

Tampilan Menu Belajar Materi dasar pramuka, didalam menu ini, aplikasi sudah menyediakan beragam materi dasar yang bisa langsung di pelajari oleh pengguna yakni mater pengenalan pancasila, pembukaan UUD 1945, Kata Sambutan Gubernur Provinsi Gorontalo, Kata Sambutan Kwarda Provinsi Gorontalo, Janji Dan Kode Moral Pramuka, Tali Temali, Morse, Mengenal Bentuk Barisan, Semaphore, Huruf Sandi, Berkemah, Atribut Pramuka, dan Struktur Pramuka seperti pada tampilan gambar 3.7 Tampilan daftar materi dasar pramuka

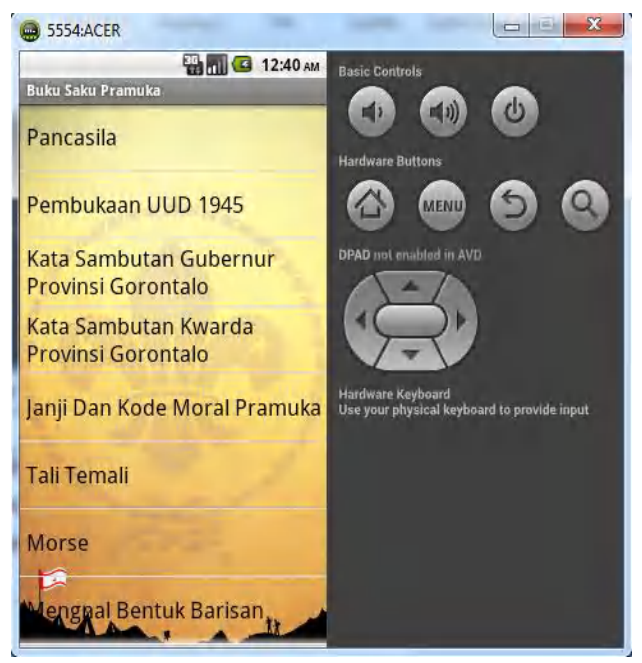

Gambar 3.7 Tampilan daftar materi dasar pramuka.

\subsubsection{Materi Pancasila}

Berikut ini adalah tampilan materi Pancasila yang sudah dipilih oleh pengguna, dalam menu ini pengguna langsung mengetahui ilmu Tentang Pancasila dan dasar dalam kepramukaan seperti pada gambar 3.8 Tampilan Materi Pancasila

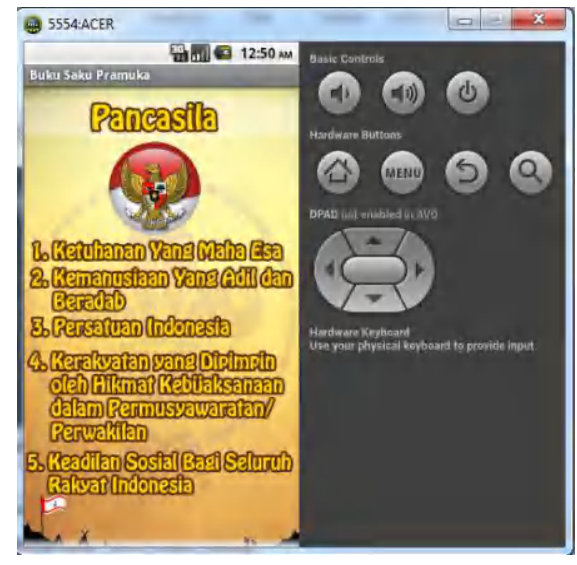

Gambar 3.8 Tampilan Materi Pancasila

\subsubsection{Materi Pembukaan UUD 1945}

Berikut ini adalah tampilan materi Pembukaan UUD 1945 yang sudah dipilih oleh pengguna, dalam menu ini pengguna langsung mengetahui ilmu Tentang Pembukaan UUd 1945 dan dasar dalam kepramukaan seperti pada gambar 3.9 Tampilan Materi Pembukaan UUD 1945.

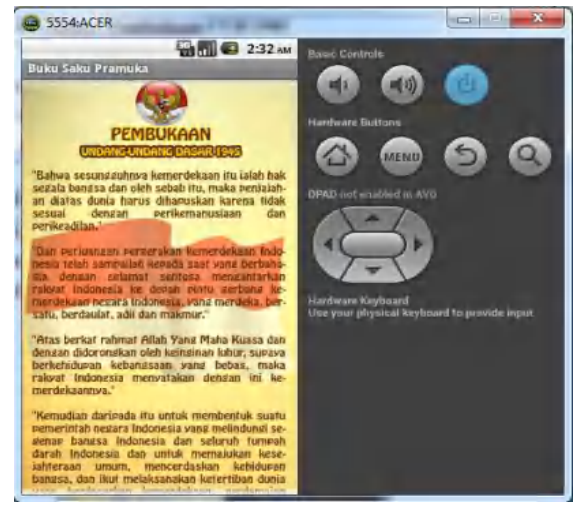

Gambar 3.9 Tampilan Materi Pembukaan UUD 1945

\subsubsection{Materi Janji Dan Kode Moral Pramuka}

Berikut ini adalah tampilan materi Janji Dan Kode Moral Pramuka yang sudah dipilih oleh pengguna, dalam menu ini pengguna langsung mengetahui ilmu Tentang Janji Dan Kode Moral Pramuka diantranya Trisatya, dasadharma Pramuka, Dwisatya, dan Dwidharma seperti pada gambar 3.10 Tampilan Materi Janji Dan Kode Moral Pramuka.

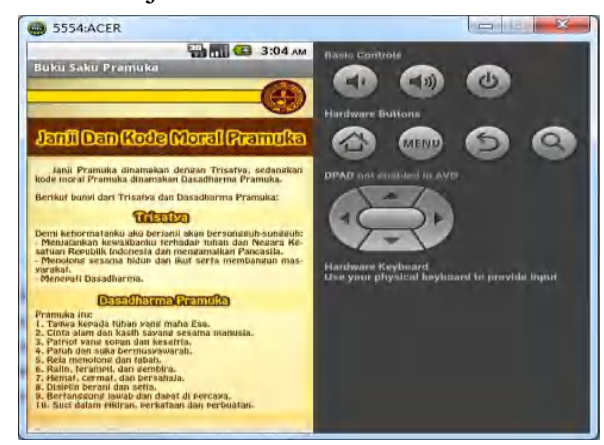

Gambar 3.10 Tampilan Materi Janji Dan Kode Moral Pramuka. 


\subsubsection{Materi Tali Temali}

Berikut ini adalah tampilan materi Tali Temali yang sudah dipilih oleh pengguna, dalam menu ini pengguna langsung mengetahui ilmu Tentang Materi Tali Temali yang diantaranya Simpul Ujung Tali, Simpul Mati, Simpul Anyam, Simpul Anyam Berganda, Simpul Simpul Pangkal seperti pada gambar 3.11 Tampilan Simpul Ujung Tali dan Tampilan Simpul Mati
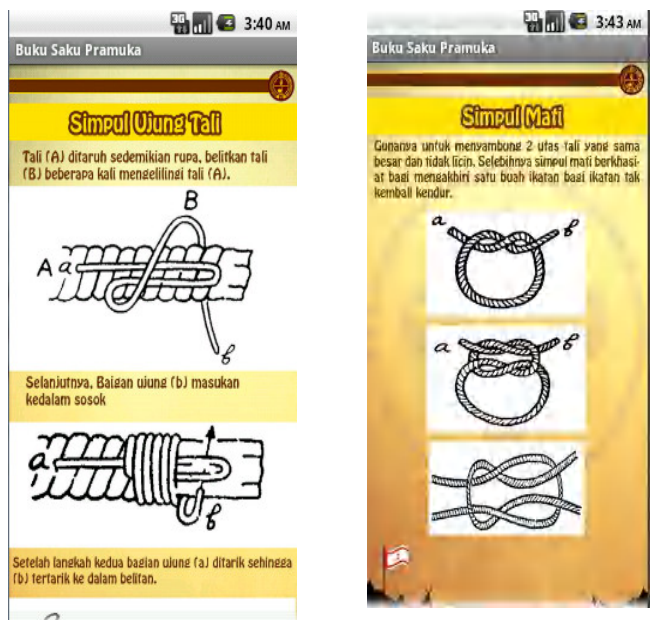

Gambar 4.1 Tampilan Simpul Ujung Tali dan Tampilan Simpul Mati

\subsubsection{Materi Morse}

Berikut ini adalah tampilan materi morse yang sudah dipilih oleh pengguna, dalam menu ini pengguna langsung mengetahui ilmu Tentang Materi Morse dimana pengguna akan lebih mengetahui panjan pendeknya bunyi tiupan pluit dengan arti tertentu gambar 3.12 Tampilan Materi Morse.

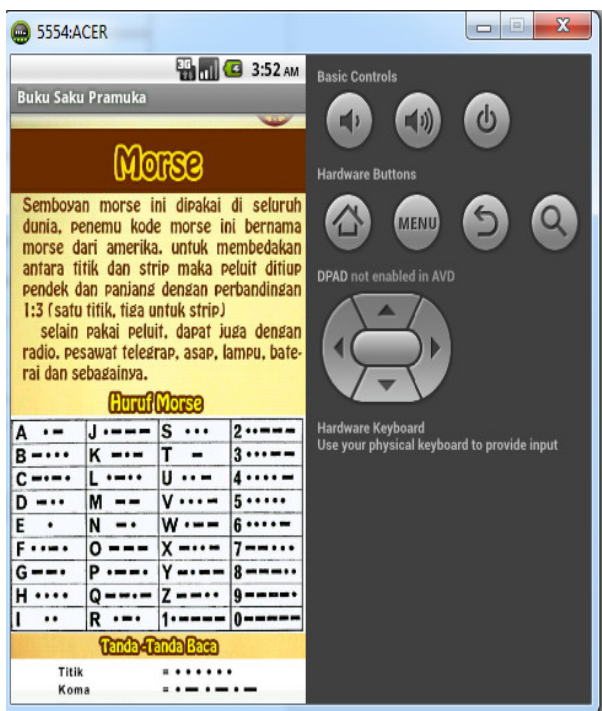

Gambar 4.2 Tampilan Materi Morse

\section{KESIMPULAN}

\subsection{Kesimpulan}

Berdasarkan hasil pengujian, aplikasi buku saku pramuka ini adalah:

1. Berdasarkan hasil pengujian yang telah dilakukan ternyata dimensi gambar sangat berpengaruh pada setiap smartphone yang diuji cobakan.

2. Berdasarkan hasil survey dan uji coba di lapangan bahawa buku saku pramuka dengan menggunakan smartphone lebih di sukai oleh masyarakat dari pada buku saku pramuka biasa.

3. Buku saku pramuka yang di uji cobakan bisa di jalankan secara offline

4. Berdasarkan hasil survey dari 16 sampel yaitu 7 orang yang memiliki smartphone dan 9 orang tidak memiliki smartphone meyatakan bahwa aplikasi buku saku pramuka ini memacu untuk mempelajari ilmu kepramukaan dibanding buku saku pramuka biasanya.

\subsection{Saran}

Adapun saran dari penulis setelah membangun aplikasi ini adalah :

1. Untuk pengembangan selanjutnya diharapkan menambahkan fitur zoom pada semua materi, karena aplikasi ini menggunakan fitur zoom hanya pada materi pengenalan atribut.

2. Untuk pengembangan selanjutnya diharapkan menambahkan animasi pada semua materi-materi, karena aplikasi menggunakan animasi baru pada materi semaphore dan bentuk barisan.

\section{DAFTAR PUSTAKA}

1. Amperiyanto Tri, 2014 " Tips Ampuh Android “, PT.Elex Media Komputindo.

2. Sunardi Bob Andri, 2013 "BOYMAN Ragam Latihan Pramuka" Nuansa Muda, Bandung. 